\title{
EFEK MORTALITAS DAN PENGHAMBATAN MAKAN BEBERAPA EKSTRAK TUMBUHAN ASAL KABUPATEN MERAUKE, PAPUA TERHADAP LARVA CROCIDOLOMIA PAVONANA (F.) (LEPIDOPTERA: CRAMBIDAE)
}

\author{
Johana Anike Mendes, Dadang, \& Endang Sri Ratna \\ Departemen Proteksi Tanaman, Fakultas Pertanian, Institut Pertanian Bogor \\ Jl. Kamper Kampus IPB Dramaga, Bogor 16680 \\ E-mail: mendesjoanna613@gmail.com
}

\begin{abstract}
Mortality and feeding inhibition effects of several plant extracts collected from Merauke Distric, Papua against Crocidolomia pavonana (F.) larvae (Lepidoptera: Crambidae). The objective of this research was to study mortality and feeding inhibition effects of several plants extract species collected from Merauke District Papua as botanical insecticides against Crocidolomia pavonana larvae. Seven plants used in the research were Areca catechu seeds (Arecaceae), Eucalyptus pellita tree barks (Myrtaceae), Myrmecodia pendans tubers (Rubiaceae), Piper aduncum fruits (Piperaceae), Piper betle leaves (Piperaceae), Pandanus conoideus fruits (Pandanaceae), and Zingiber officinale rhizomes (Zingiberaceae). Each plant extract was tested to $2^{\text {nd }}$ instar $C$. pavonana larvae. The insecticidal activities were assessed including mortality and feeding inhibition activities. Extract concentrations for mortality tests using topical application method were $0,1 \%, 0,5 \%, 1 \%, 2 \%$, and control, while extract concentrations for feeding inhibition tests using choice and no choice methods were $0,25 \%, 0,5 \%, 1 \%, 2 \%$, and control. Each treatment was introduced to ten C. pavonana larvae and replicated five times. The results showed that $P$. aduncum and P. conoideus fruits extracts gave $100 \%$ mortality at $2 \%$ rate. Extract of $P$. betle leaf at $2 \%$ rate totally inhibited feeding activity of larvae (100\%) using choice method, while extract of $Z$. officinale rhizome at $2 \%$ rate resulted in moderate feeding inhibition effect (75\%) using no choice method.
\end{abstract}

Key words: botanical insecticides, feeding inhibition, mortality, plant extracts

\begin{abstract}
ABSTRAK
Efek mortalitas dan penghambatan makan beberapa ekstrak tumbuhan asal Kabupaten Merauke, Papua terhadap larva Crocidolomia pavonana (F.) (Lepidoptera: Crambidae). Tujuan penelitian ini adalah menguji pengaruh terhadap mortalitas dan penghambatan aktivitas makan dari beberapa ekstrak tumbuhan asal Kabupaten Merauke Papua sebagai insektisida nabati terhadap larva Crocidolomia pavonana. Tujuh spesies tumbuhan yang digunakan dalam penelitian adalah biji Areca catechu (Arecaceae), kulit kayu Eucalyptus pellita (Myrtaceae), umbi Myrmecodia pendans (Rubiaceae), buah Piper aduncum (Piperaceae), daun Piper betle (Piperaceae), buah Pandanus conoideus (Pandanaceae) dan rimpang Zingiber officinale (Zingiberaceae). Aktivitas insektisida yang diuji meliputi mortalitas dan penghambatan aktivitas makan. Ekstrak diuji pada empat taraf konsentrasi dan kontrol berdasarkan uji pendahuluan. Konsentrasi untuk pengujian mortalitas menggunakan metode perlakuan topikal adalah $0,1 \%, 0,5 \%, 1 \%, 2 \%$, dan kontrol, sedangkan konsentrasi untuk pengujian penghambat makan adalah $0,25 \%, 0,5 \%, 1 \%, 2 \%$, dan kontrol dengan metode pilihan dan tanpa pilihan. Sepuluh larva C. pavonana instar II digunakan untuk tiap perlakuan dan tiap perlakuan diulang sebanyak lima kali. Hasil penelitian menunjukkan ekstrak buah $P$. aduncum dan $P$. conoideus memberikan pengaruh mortalitas masing-masing $100 \%$ pada konsentrasi $2 \%$. Ekstrak daun $P$. betle pada konsentrasi $2 \%$ menghambat aktivitas makan larva secara total (100\%) menggunakan metode pilihan, sementara itu ekstrak rimpang Z. officinale pada konsentrasi $2 \%$ memberikan penghambatan aktivitas makan larva sedang $(75 \%)$ menggunakan metode tanpa pilihan.
\end{abstract}

Kata kunci: ekstrak tumbuhan, insektisida nabati, mortalitas, penghambatan makan 


\section{PENDAHULUAN}

Crocidolomia pavonana (F.) (Lepidoptera: Crambidae) merupakan salah satu hama utama pada tanaman famili Brassicaceae. Serangan hama tersebut dapat menyebabkan kerusakan hingga $100 \%$ jika tidak dilakukan tindakan pengendalian (Mulyaningsih, 2010). Tindakan pengendalian yang umum dilakukan oleh petani adalah dengan menggunakan insektisida sintetik (Dono et al., 2010) yang oleh petani dianggap lebih praktis, efektif, dan efisien dari segi waktu, biaya, dan tenaga kerja (Dadang \& Prijono, 2008). Namun penggunaan insektisida sintetik secara terus menerus dengan intensitas yang tinggi dan teknik aplikasi yang kurang tepat dapat menimbulkan beberapa dampak negatif, seperti terjadinya resistensi hama, ledakan hama sekunder, terbunuhnya organisme bukan sasaran dan kandungan residu insektisida pada produk pertanian.

Salah satu alternatif cara pengendalian hama yang ramah lingkungan yaitu dengan menggunakan insektisida nabati. Insektisida nabati merupakan insektisida berbahan aktif senyawa metabolit sekunder dari tumbuhan yang mempunyai kemampuan untuk mempengaruhi aktivitas biologi, fisiologi, dan perilaku serangga hama (Dadang \& Prijono, 2008). Tumbuhan mampu memproduksi beberapa golongan senyawa metabolit sekunder seperti alkaloid, fenol, terpenoid, flavonoid, dan senyawa lainnya yang dapat berfungsi sebagai pertahanan diri (self defense) bagi tumbuhan itu sendiri. Metabolit sekunder tumbuhan berpotensi untuk dimanfaatkan sebagai agens perlindungan tanaman. Menurut Dadang \& Prijono (2008), beberapa kelebihan penggunaan insektisida nabati adalah senyawa kimia yang terkandung mudah terurai di alam (biodegradable) dan relatif aman terhadap organisme bukan sasaran. Menurut Leslie (1994), insektisida nabati memiliki efek fitotoksik yang rendah bagi tanaman yang dibudidayakan.

Kabupaten Merauke merupakan salah satu kabupaten yang berada dalam wilayah administratif Provinsi Papua. Pada umumnya masyarakat Merauke memanfaatkan sumber daya alam (flora) yang tersebar di daerah tersebut sebagai sumber mata pencaharian, bahan pangan, bahan sandang, dan dimanfaatkan sebagai obat dalam pengobatan tradisional yang menjadi cermin dari budaya dan adat istiadat masyarakat setempat. Beberapa famili tumbuhan yang tersebar di Kabupaten Merauke antara lain Arecaceae, Myrtaceae, Pandanaceae, Piperaceae, Rubiaceae, dan Zingiberaceae. Komponen kimia yang bersumber dari famili tersebut diduga berpotensi sebagai insektisida. Oleh karena itu perlu dilakukan penelitian untuk menguji keefektifan ekstrak tumbuhan yang berasal dari Kabupaten Merauke, Papua terhadap tingkat mortalitas dan penghambatan makan larva C. pavonana.

\section{METODE PENELITIAN}

Tempat dan Waktu. Penelitian dilaksanakan di Laboratorium Fisiologi dan Toksikologi Serangga, Departemen Proteksi Tanaman, Fakultas Pertanian, Institut Pertanian Bogor (IPB) pada bulan Januari sampai September 2015.

Bahan Sumber Ekstrak. Bahan tumbuhan yang digunakan sebagai sumber ekstrak adalah biji pinang (Areca catechu) (Arecaceae), kulit kayu Eucalyptus pellita (Myrtaceae), umbi sarang semut (Myrmecodia pendans) (Rubiaceae), daun sirih (Piper betle) (Piperaceae), buah sirih hutan (Piper aduncum) (Piperaceae), buah merah (Pandanus conoideus) (Pandanaceae), dan rimpang jahe merah (Zingiber officinale) (Zingiberaceae) yang berasal dari Desa Wasur Kecamatan Merauke, Desa Kondo Kecamatan Noken Njerai dan Desa Kurik Kecamatan Kurik Kabupaten Merauke, Papua.

Perbanyakaan Tanaman Pakan. Daun brokoli (Brassica oleracea) digunakan sebagai pakan serangga uji dan sebagai media perlakuan. Perbanyakan tanaman brokoli dimulai dari proses pembibitan yang dilakukan pada nampan yang berisi media campuran tanah dan pupuk organik $(1: 1 \mathrm{v} / \mathrm{v})$. Bibit yang telah memiliki sekurang-kurangnya empat lembar helai daun dipindahkan ke polybag kapasitas $5 \mathrm{~kg}$ yang diisi campuran tanah dan pupuk kandang (3:1 v/v). Daun yang digunakan sebagai pakan larva $C$. pavonana berasal dari tanaman brokoli yang telah berumur 2 bulan.

Perbanyakan Serangga Uji. Serangga $C$. pavonana yang digunakan dalam penelitian ini berasal dari Desa Gandamanah Kecamatan Cisarua Kabupaten Bogor Jawa Barat. Prosedur pembiakan serangga dilakukan berdasarkan Prijono \& Hasan (1992). Larva $C$. pavonana diberi pakan daun brokoli dan imagonya diberi pakan larutan madu $10 \%$ yang diserapkan pada kapas dan digantung di dalam kurungan serangga $(50 \times 50 \times 50$ $\mathrm{cm})$.

Daun brokoli digunakan sebagai media peletakan telur yang bagian tangkainya dimasukkan ke dalam tabung rol film berisi air dan diletakkan di dalam kurungan. Kelompok telur yang diletakkan dikumpulkan 
setiap hari. Setelah telur menetas, larva dipindahkan ke dalam kotak plastik $(10 \times 7 \times 5 \mathrm{~cm})$ berjendela kasa dan diberi pakan daun brokoli secukupnya. Larva instar II digunakan untuk pengujian.

\section{Ekstraksi Bahan Tumbuhan Sumber Ekstrak.} Bagian tumbuhan yang digunakan sebagai sumber ekstrak dikeringanginkan terlebih dahulu selama beberapa hari kemudian dihaluskan dengan blender, diayak menggunakan pengayak kawat berjalinan $0,5 \mathrm{~mm}$ hingga didapatkan serbuk halus. Sebanyak $200 \mathrm{~g}$ masingmasing serbuk direndam dalam 2 liter metanol, kecuali serbuk buah $P$. aduncum direndam dalam 2 liter etil asetat. Hasil rendaman disaring menggunakan corong kaca yang telah dilapisi dengan kertas saring dan diuapkan menggunakan rotary evaporator pada suhu $50{ }^{\circ} \mathrm{C}$ dan tekanan 337 mbar. Pelarut hasil penguapan yang diperoleh digunakan kembali untuk merendam sisa ampas hasil saringan dengan prosedur yang sama sesuai dengan uraian di atas. Ekstrak kasar yang diperoleh disimpan di dalam lemari es hingga digunakan untuk pengujian.

\section{Metode Pengujian}

Uji Toksisitas. Pengujian dilakukan menggunakan metode perlakuan topikal. Ekstrak diuji pada empat taraf konsentrasi dan kontrol. Taraf konsentrasi uji yang digunakan ialah $0,1 \%, 0,5 \%, 1 \%, 2 \%$ dan kontrol. Setiap perlakuan dan kontrol diulang lima kali. Sediaan ekstrak buah $P$. aduncum, daun $P$. betle, buah $P$. conoideus dan rimpang $Z$. officianale dilarutkan dalam campuran pelarut metanol ditambah pengemulsi Tween80 (5:1 v/v), sementara itu sediaan ekstrak biji A. catechu dan kulit kayu $E$. pellita dilarutkan dalam campuran pelarut etanol dan Tween $80(5: 1 \mathrm{v} / \mathrm{v})$. Sediaan ekstrak umbi $M$. pendans dilarutkan dalam pelarut etanol dan pengemulsi Agristik (5:1 v/v). Masing-masing ekstrak terlarut kemudian ditambahi akuades hingga volume tertentu sesuai dengan konsentrasi uji yang digunakan. Sebanyak 10 ekor larva $C$. pavonana dimasukkan ke dalam cawan petri berdiameter $9 \mathrm{~cm}$. Sediaan ekstrak uji diteteskan pada bagian dorsal toraks larva menggunakan microsyringe, kemudian larva diberi dua potong daun brokoli $(4 \times 4 \mathrm{~cm})$ tanpa perlakuan sebagai pakan serangga uji. Pengamatan dilakukan pada 24, 48 dan 72 jam setelah perlakuan (JSP) dengan menghitung jumlah larva yang mati. Data mortalitas kumulatif (72 jam) diolah dengan analisis probit menggunakan program POLOPC (LeOra Sofware, 1987). Data pengamatan 72 JSP di input dalam program kemudian ditulis nilai LC yang diinginkan dengan perintah-perintah dalam program tersebut hingga diperoleh outputnya, kemudian digunakan nilai LC 50 dan LC 95 sebagai indikator toksisitas dengan selang kepercayaan $95 \%$.

Uji Penghambatan Makan. Pengujian dilakukan menggunakan metode pilihan dan tanpa pilihan. Ekstrak diuji pada empat taraf konsentrasi yaitu $0,25 \%, 0,5 \%$, $1 \%$ dan $2 \%$, serta kontrol. Penyiapan sediaan ekstrak yang akan digunakan mempunyai tahapan yang sama dengan sediaan ekstrak pada pengujian toksisitas yang telah diuraikan sebelumnya.

Pada metode pilihan, pengujian menggunakan empat lembar potong daun brokoli $(4 \times 4 \mathrm{~cm})$. Dua potong daun brokoli dicelupkan ke dalam sediaan ekstrak uji, sedangkan dua potong daun lainnya dicelupkan ke dalam sediaan larutan kontrol dan dikeringudarakan selama beberapa menit. Potongan daun yang telah dikeringudarakan disusun dalam cawan petri berdiameter $14 \mathrm{~cm}$. Sebanyak 10 ekor larva $C$. pavonana instar II dimasukkan ke dalam cawan petri dan dibiarkan makan selama 24 jam dan diulang sebanyak lima kali. Setelah 24 jam sisa potongan daun diambil, dioven pada suhu $105{ }^{\circ} \mathrm{C}$ selama 2 jam kemudian ditimbang untuk menentukan berat kering dan dilanjutkan dengan perhitungan persentase penghambat makan. Persen penghambat aktivitas makan dengan metode pilihan dihitung menggunakan rumus Prijono (2005):

$$
P M=\frac{\mathrm{BKK}-\mathrm{BKP}}{\mathrm{BKK}+\mathrm{BKP}} \times 100 \%
$$

dengan:

$\mathrm{PM}=$ Penghambatan makan (\%)

BKK = Berat kering daun kontrol yang dimakan $(\mathrm{g})$

$\mathrm{BKP}=$ Berat kering daun perlakuan yang dimakan $(\mathrm{g})$

Pada metode tanpa pilihan, digunakan empat potong daun brokoli $(4 \times 4 \mathrm{~cm})$. Dua lembar daun dicelupkan ke dalam sediaan larutan ekstrak uji, sementara itu dua lembar daun lainnya dicelup dalam sediaan larutan kontrol. Kemudian dikeringudarakan selama beberapa menit. Setelah dikeringudarakan, dimasukkan masing-masing 2 potong daun perlakuan dan kontrol pada cawan petri berdiameter $9 \mathrm{~cm}$ secara terpisah. Sebanyak 10 ekor larva C. pavonana instar II dimasukkan ke dalam cawan petri dan dibiarkan makan selama 24 jam, setiap perlakuan diulang sebanyak lima kali. Setelah 24 jam sisa potongan daun kemudian dioven pada suhu $105{ }^{\circ} \mathrm{C}$ selama 2 jam kemudian ditimbang untuk menentukan berat kering dan dilanjutkan dengan 
menghitung persen penghambat aktivitas makan. Persen penghambat makan dengan metode tanpa pilihan dihitung menggunakan rumus Prijono (2005):

$$
P M=\frac{\mathrm{BKK}-\mathrm{BKP}}{\mathrm{BKK}} 100 \%
$$

dengan:

$\mathrm{PM}=$ Penghambatan makan (\%)

$\mathrm{BKK}=$ Berat kering daun kontrol yang dimakan $(\mathrm{g})$

$\mathrm{BKP}=$ Berat kering daun perlakuan yang dimakan $(\mathrm{g})$

Persentase penghambat makan yang telah dihitung akan dilanjutkan dengan menentukan kriteria penghambat makan (Tabel 1).

\section{HASIL DAN PEMBAHASAN}

\section{Pengujian Toksisitas}

Metode Perlakuan Topikal. Pengujian masingmasing ekstrak dengan metode topikal mampu menyebabkan mortalitas larva $C$. pavonana yang beragam. Mortalitas tertinggi ditunjukkan pada perlakuan ekstrak $P$. aduncum dan $P$. conoideus. Perlakuan ekstrak P. aduncum menyebabkan mortalitas larva antara $36 \%$ sampai $100 \%$, sementara itu mortalitas larva C. pavonana akibat perlakuan ekstrak P. conoideus sebesar $12 \%$ sampai $100 \%$. Perlakuan ekstrak lainnya menunjukkan bahwa persen mortalitas larva uji pada perlakuan ekstrak biji $A$. catechu sebesar $0 \%$ sampai $44 \%$ lebih tinggi dibandingkan perlakuan ekstrak kulit kayu E. pellita

Tabel 1. Kriteria penghambat makan

\begin{tabular}{cc}
\hline Penghambat makan $(\%)$ & Kriteria \\
\hline$\geq 80$ & Kuat \\
$61 \leq \mathrm{x}<80$ & Sedang \\
$40 \leq \mathrm{x}<60$ & Lemah \\
$<40$ & Sangat lemah \\
\hline
\end{tabular}

Sumber: Park et al.,(1997)

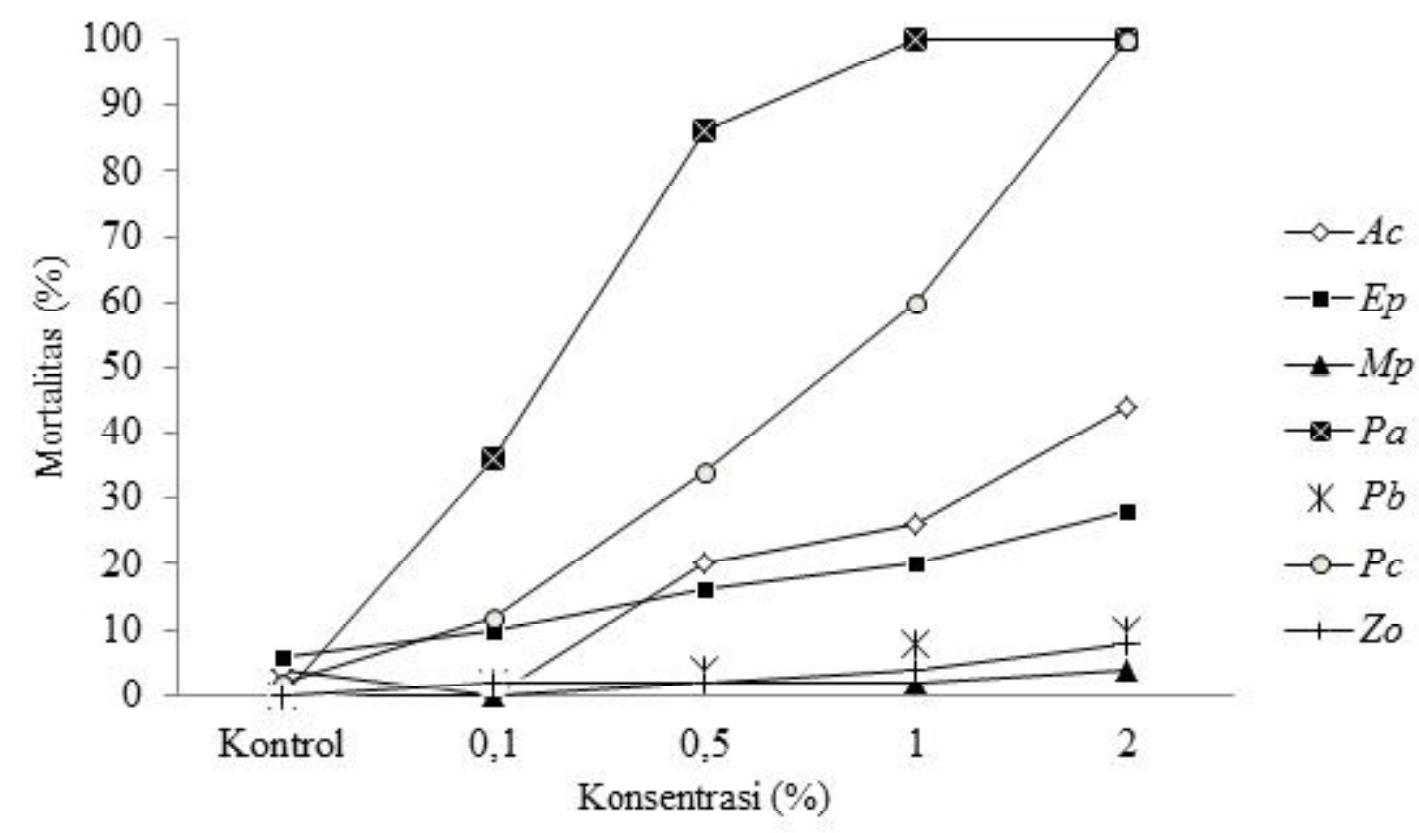

Gambar 1. Mortalitas $C$. pavonana yang diperlakukan beberapa ekstrak tumbuhan dengan metode perlakuan topikal (Ac: Areca catechu, Ep: Eucalyptus pellita, Mp: Myrmecodia pendens, Pa: Piper aduncum, Pb: Piper betle, Pc: Pandanus conoideus, Zo: Zingiber officinale) 
dengan mortalitas sebesar 10\% sampai 28\% (Gambar 1). Ekstrak umbi M. pendans, daun P. betle, dan rimpang $Z$. officinale menunjukkan persen mortalitas yang rendah. Hal ini menunjukkan bahwa ekstrak $P$. aduncum dan $P$. conoideus memiliki efek kontak yang cukup tinggi dibandingkan ekstrak lainnya.

Lina (2014) melaporkan bahwa komponen utama yang terkandung dalam minyak atsiri ekstrak buah $P$. aduncum ialah dilapiol. Senyawa dilapiol bersifat sebagai racun metabolik (Bernard et al., 1995) dan mempunyai struktur yang mampu menghambat kerja enzim detoksifikasi (Bernard et al., 1989). Penghambatan disebabkan karena adanya senyawa lignan yang mengandung gugus metilendioksifenil dan merupakan ciri sebagai senyawa sinergis yang dapat menghambat aktivitas enzim sitokrom P450 (Scott et al., 2008). Bernard et al.(1990) melaporkan bahwa dilapiol yang berasal dari $P$. aduncum dapat menghambat aktivitas enzim sitokrom P450 dalam sediaan mikrosom dari selsel saluran pencernaan larva penggerek batang jagung Ostrinia nubilalis (Lepidoptera: Pyralidae). Untuk itu, kematian larva $C$. pavonana pada pengujian ini diduga akibat kerja senyawa dilapiol yang terkandung di dalam ekstrak $P$. aduncum.

Rohman et al. (2010) melaporkan bahwa ekstrak metanol buah $P$. conoideus mengandung golongan senyawa fenol sebanyak 80,27 mg/g ekstrak. Ekstrak daun Cerbera odollam (Gentianales: Apocynaceae) mengandung metabolit sekunder yaitu seyawa fenol yang memiliki fungsi untuk merangsang makan pada serangga Spodoptera litura (F) (Lepidoptera: Noctuidae) akibatnya senyawa yang bersifat racun dalam kandungan ekstrak $C$. odollam dapat terakumulasi di dalam tubuh $S$. litura dan mampu menyebabkan penghambatan pertumbuhan (Sa'diyah et al., 2013). Berkaitan dengan hasil penelitian ini, diduga karena adanya senyawa flavonoid yang terkandung di dalam ekstrak $P$. conoideus sehingga mampu menyebabkan mortalitas terhadap larva C. pavonana.

Aktivitas ketujuh ekstrak tergambar dari parameter regresi probit yang menunjukkan hubungan konsentrasi dan mortalitas C. pavonana (Tabel 2). Berdasarkan nilai $\mathrm{LC}_{95}, P$. aduncum menunjukkan aktivitas yang paling kuat kemudian diikuti oleh $P$. conoideus sedangkan untuk lima ekstrak lainnya tidak menunjukkan hubungan. Kemiringan garis regresi ekstrak $P$. aduncum lebih tinggi dibandingkan keenam jenis ekstrak lainnya. Hal ini menunjukkan bahwa peningkatan konsentrasi ekstrak pada jumlah tertentu mampu meningkatkan mortalitas serangga $C$. pavonana pada perlakuan ekstrak $P$. aduncum yang lebih tinggi dari pada perlakuan ekstrak lainnya.

\section{Pengujian Penghambatan Makan}

Metode Pilihan. Pengujian penghambatan makan dengan metode pilihan terhadap tujuh ekstrak tumbuhan, masing-masing pada empat taraf konsentrasi menunjukkan pengaruh penghambatan makan terhadap larva $C$. pavonana instar II yang beragam dan dapat dikategorikan kuat, sedang dan lemah (Tabel 3). Ekstrak $P$. betle menunjukkan pengaruh penghambatan makan dengan kriteria kuat pada semua konsentrasi uji bahkan pada konsentrasi $2 \%$ mampu menghambat aktivitas makan larva secara total (100\%). Ekstrak lain yang memberikan penghambatan aktivitas makan dengan kriteria kuat yaitu dengan persen penghambatan makan sama dengan atau lebih besar dari $80 \%$ adalah ekstrak A. catechu pada konsentrasi $0,5 \%, 1 \%$ dan $2 \%, E$.

Tabel 2. Parameter regresi probit hubungan konsentrasi ekstrak beberapa tumbuhan dengan mortalitas larva $C$. pavonana

\begin{tabular}{|c|c|c|c|}
\hline Jenis ekstrak & $b \pm \mathrm{SE}$ & $\begin{array}{c}\mathrm{LC}_{50} \\
(\mathrm{SK} 95 \%)(\%)\end{array}$ & $\begin{array}{c}\mathrm{LC}_{95} \\
(\mathrm{SK} 95 \%)(\%)\end{array}$ \\
\hline A. catechu & $1,66 \pm 0,38$ & $2,57 \quad(-)$ & $24,96 \quad(-)$ \\
\hline E. pellita & $0,79 \pm 0,40$ & $18,03 \quad(-)$ & $2153,42 \quad(-)$ \\
\hline M. pendans & $0,85 \pm 0,65$ & $216,24 \quad(-)$ & $18569,00(-)$ \\
\hline P. aduncum & $2,45 \pm 0,33$ & $0,14(0,04-0,26)$ & $0,68(0,35-5,95)$ \\
\hline P. betle & $0,51 \pm 0,36$ & $205,09 \quad(-)$ & $81163,00(-)$ \\
\hline P. conoideus & $3,61 \pm 1,14$ & $0,70 \quad(-)$ & $2,02 \quad(-)$ \\
\hline Z. officinale & $0,55 \pm 0,39$ & $1082,62(-)$ & - \\
\hline
\end{tabular}

$a=$ intersep garis regresi probit; $b=$ kemiringan regresi; $\mathrm{SE}=$ standar error $; \mathrm{LC}=$ lethal concentration $; \mathrm{SK}=$ selang kepercayaan; (-) pada hasil uji penghambatan makan menunjukkan tidak adanya proses penghambatan makan pada pengujian ekstrak terhadap larva $C$. pavonana. 
pellita pada konsentrasi $2 \%$, dan Z. officinale pada konsentrasi $1 \%$ dan $2 \%$. Sementara itu perlakuan ekstrak yang menghasilkan penghambatan makan dengan kriteria sedang adalah ekstrak $A$. catechu pada konsentrasi $0,25 \%, E$. pellita pada konsentrasi $1 \%$ dan ekstrak $M$. pendans pada konsentrasi $1 \%$ dan $2 \%$. Hal ini menunjukkan bahwa $P$. betle memiliki efek penghambat makan yang lebih tinggi dibandingkan dengan ekstrak tumbuhan lainnya pada uji dengan metode pilihan.

Menurut Prakash et al. (2010), ekstrak P. betle mengandung $97 \%$ minyak. Dalam minyak tersebut terkandung 32 komponen senyawa yang berbeda. Senyawa eugenol $(63,39 \%)$ dan senyawa fenol seperti cavibetol $(53,1 \%)$ merupakan komponen utama. Komponen senyawa yang terkandung di dalam minyak tersebut diduga sebagai faktor yang mempengaruhi penghambatan makan larva $C$. pavonana. Menurut Scott et al. (2008) senyawa sekunder yang berasal dari spesies Piperaceae bersifat menghambat makan terhadap serangga. Penghambatan aktivitas makan larva $C$. pavonana oleh ekstrak $P$. betle menunjukkan persen paling tinggi pada semua konsentrasi uji. Hal ini menunjukkan bahwa ekstrak $P$. betle memiliki pengaruh penghambat makan yang baik terhadap larva $C$. pavonana.

Metode Tanpa Pilihan. Pengujian penghambatan makan dengan tujuh ekstrak tumbuhan, masing-masing pada empat taraf konsentrasi menunjukkan bahwa enam ekstrak tumbuhan tidak memberikan pengaruh penghambatan makan terhadap larva C. pavonana instar II (Tabel 3). Ekstrak Z. officinale menunjukkan adanya pengaruh penghambatan makan dengan kriteria sedang yaitu $75 \%$ pada konsentrasi $2 \%$, sedangkan konsentrasi rendah menunjukkan pengaruh penghambatan makan dengan kriteria sangat lemah (Tabel 3). Pengaruh ekstrak uji lain tidak menunjukkan adanya aktivitas penghambatan makan terhadap larva $C$. pavonana. Hal ini menunjukkan bahwa ekstrak $Z$. officinale memiliki efek penghambat makan yang lebih tinggi dibandingkan dengan ekstrak tumbuhan lainnya pada metode tanpa pilihan.

Senyawa kimia utama yang terkandung dalam ekstrak rimpang $Z$. officinale antara lain senyawa gingerol, shogaol, paradol, isogingerol, isoshogaol dan gingerdione (Ali et al., 2008). Jahe merah juga mengandung komponen senyawa volatil yang terdiri dari beberapa senyawa sesquiterpen dan monoterpen yang mampu memberikan aroma khas pada jahe merah. Menurut Asfi et al. (2015), senyawa aktif zingiberne pada filtrat jahe merah akan menstimulus reseptor penghalang yang dapat mempengaruhi pengiriman sinyal antimakan pada saraf pusat serangga. Dampak yang terjadi yaitu dapat mengganggu hantaran implus pada sistem saraf serangga sehingga serangga uji tidak dapat mendeteksi keberadaan makanan di sekitarnya.

Komponen penghambatan makan yang dikandung dalam tanaman dapat dideteksi serangga melalui sistem indra atau akibat rangsangan melalui saraf pusat serangga yang mengatur proses makan. Tingginya penghambatan

Tabel 3. Persen penghambatan aktivitas makan beberapa ekstrak tumbuhan terhadap larva C. pavonana dengan metode pilihan dan tanpa pilihan

\begin{tabular}{ccccccccc}
\hline \multirow{2}{*}{ Metode pengujian } & Konsentrasi & \multicolumn{7}{c}{ Jenis ekstrak } \\
\cline { 3 - 8 } & $(\%)$ & Ac & Ep & Mp & Pa & Pb & Pc & Zo \\
\hline \multirow{3}{*}{ Pilihan } & 0,25 & 79 & 47 & 51 & 29 & 88 & 38 & 50 \\
& 0,5 & 81 & 53 & 55 & 32 & 94 & 40 & 58 \\
& 1 & 82 & 62 & 68 & 32 & 97 & 42 & 83 \\
& 2 & 83 & 81 & 75 & 41 & 100 & 54 & 93 \\
\hline \multirow{3}{*}{ Tanpa pilihan } & 0,25 & -16 & -14 & -53 & -38 & -10 & -32 & -16 \\
& 0,5 & -12 & -19 & -16 & -42 & -12 & -39 & 3 \\
& 1 & -9 & -19 & -25 & -43 & -1 & -40 & 2 \\
& 2 & 6 & -20 & -37 & -38 & 7 & -27 & 75 \\
\hline
\end{tabular}

(Ac : Areca catechu, Ep: Eucalyptus pellita, Mp: Myrmecodia pendens, $\mathrm{Pa}$ : Piper aduncum, Pb: Piper betle, Pc: Pandanus conoideus, Zo: Zingiber officinale) 
aktivitas makan ini dapat memberikan pengaruh yang sinergis antar ekstrak dimana aktivitas makan akan memperlambat atau mengurangi jumlah makanan yang dimakan oleh serangga uji yang dapat melemahkan kondisi tubuh serangga tersebut dan jika serangga uji memakan daun-daun perlakuan yang mengandung racun maka serangga akan mengalami kematian yang lebih cepat.

\section{SIMPULAN}

Ekstrak buah $P$. aduncum dan $P$. conoideus menyebabkan mortalitas larva $C$. pavonana sebesar $100 \%$ pada konsentrasi $2 \%$ dengan metode perlakuan topikal. Ekstrak daun P. betle konsentrasi 2\% mampu menghambat aktivitas makan larva sebesar $100 \%$ dengan metode pilihan dan ekstrak rimpang $Z$. officinale mampu menghambat makan larva $C$. pavonana sebesar $75 \%$ dengan metode tanpa pilihan.

\section{SANWACANA}

Ucapan terima kasih penulis sampaikan kepada Direktorat Jenderal Pendidikan dan Kebudayaan Republik Indonesia atas bantuan Beasiswa Unggulan (BU) yang sangat membantu penulis dalam menyelesaikan penelitian ini. Ucapan terima kasih juga penulis ucapkan kepada Ir. Djoko Prijono, MAgrSc. sebagai Kepala Laboratorium Fisiologi dan Toksikologi Serangga Departemen Proteksi Tanaman IPB yang telah memberikan izin penggunaan laboratorium selama penelitian berlangsung.

\section{DAFTAR PUSTAKA}

Ali BH, Blunden G, Tanira MO, \& Nemmar A. 2008. Some phytochemical, pharmacological and toxicological properties of ginger (Zingiber officinale Roscoe): A review of recent research. Food and Chem Toxicol 46(2): 409-420.

Asfi SH, Rahayu YS, \& Yuliani. 2015. Uji bioaktivitas filtrate rimpang jahe merah (Zingiber officinale) terhadap tingkat mortalitas dan penghambatan aktivitas makan larva Plutella xylostella secara in vitro. J. Lentera Biol. 4(1): 50-55.

Bernard CB, Arnason JT, Philogene BJR, Lam J \& Waddell T. 1989. Effect of lignans and other secondary metabolites of the asteraceae on the mono-oxygenase activity of the European corn borer. Phytochemistry 28(5): 1373-1378.
Bernard CB, Arnason JT, Philogene BJR, Lam J \& Waddell T. 1990. In vivo effect of mixtures of allelochemicals on the life cycle of the European corn borer, Ostrinia nubilalis. Entomol. Exp. Appl. 57(1): 17-22.

Bernard CB, Krishanmurty HG, Chauret D, Durst T, Philogene BJR, Sanchez-vindas P, Hasbun C, Poveda L, San Roman L, \& Anarson JT. 1995. Insecticidal defenses of Piperaceae from the neotropics. J. Chem. Ecol. 21(6): 801-814.

Dadang \& Prijono D. 2008. Insektisida Nabati Prinsip, Pemanfaatan dan Pengembangan. Departemen Proteksi Tanaman. Fakultas Pertanian. IPB. Bogor.

Dono D, Ismayana S, Idar, Prijono D, \& Muslikha I. 2010. Status dan mekanisme resistensi biokimia C. pavonana (F) (Lepidoptera: Crambidae) terhadap insektisida organofosfat serta kepekaannya terhadap insektisida botani ekstrak biji Barringtonia asiatica. J. Entomol. Indon.7(1): 9-27.

LeOra Software. 1987. POLO-PC User's Guide. LeOra Software. Berkeley (UK).

Leslie AR. 1994. Handbook of Integrated Pest Management for Turf and Ornamentals. CRC Press [Internet]. [diunduh 7 April 2015].

Lina EC. 2014. Pengembangan formulasi insektisida nabati berbahan ekstrak Brucea javanica, Piper aduncum, dan Tephrosia vogelii untuk pengendalian hama kubis Crocidolomia pavonana. [disertasi]. Institut Pertanian Bogor: Bogor.

Mulyaningsih L. 2010. Aplikasi agensia hayati atau insektisida dalam pengendalian hama Plutella xylostella Linn dan Crocidolomia pavonana Zell untuk peningkatan produksi kubis (Brassica oleracea L.). J. Media Soerjo. 7(2): 91-111.

Park JS, Lee SC, Shin BY, Lee \& Ahn YJ. 1997. Larvicidal and antifeeding activities of oriental medicinal plant extracts against four species of forest insect pests. Appl. Entomol. Zool. 32(4): 601-608.

Prakash B, Shukla R, Singh P, Kumar A, Mishra PK \& Dubey NK. 2010. Efficacy of chemically characterized Piper betle L. essential oil against fungal and aflatoxin contamination of some edible commodities and its antioxidant activity. Int. J. Food Microbiol. 142(1-2): 114-119. 
Prijono D \& Hassan E. 1992. Life cycle and demography of Crocidolomia binotalis Zell. (Lepidoptera: Pyralidae) on broccoli in the laboratory. Indon. J. Trop. Agric. 4(1): 18-24.

Prijono D. 2005. Pengembangan dan pemanfaatan insektisida botani (Bahan Pelatihan). Departemen Proteksi Tanaman Fakultas Pertanian Institut Pertanian Bogor. Bogor.

Rohman A, Riyanto S, Yuniarti N, Saputra WR, Utami R, \& Mulatsih W. 2010. Antioxidant activity, total phenolic, and total flavonoid of extracts andfractions of red fruit (Pandanus conoideus). Int. Food Res. J. 17: 97-106.
Sa'diyah NA, Purwani KI, \& Wijayawati L. 2013. Pengaruh ekstrak daun bintaro (Cerbera odollam) terhadap perkembangan ulat grayak (Spodoptera litura F). J. Sains dan Seni Pomits. 2(2): 2337-3520.

Scott IM, Jensen HR, Philogene BJR \& Arnason JT. 2008. A review of Piper spp. (Piperaceae) phytochemistry, insecticidal activity and mode of action. Phytochem. Rev. 7: 65-75. 